\title{
Vascular Remodeling and Arterial Calcification Are Directly Mediated by S100A12 (EN-RAGE) in Chronic Kidney Disease
}

\author{
Joseph Gawdzik $^{\mathrm{a}}$ Liby Mathew ${ }^{\mathrm{b}} \quad$ Gene Kim $^{\mathrm{a}}$ Tipu S. Puri ${ }^{\mathrm{b}}$ \\ Marion A. Hofmann Bowman ${ }^{a}$ \\ Sections of a Cardiology and ${ }^{b}$ Nephrology, Department of Medicine, University of Chicago, Chicago, III., USA
}

\section{Key Words}

Chronic kidney disease $\cdot$ Blood urea nitrogen •

Receptor for advanced glycation endproducts

\begin{abstract}
Background: The proinflammatory cytokine S100A12 (also known as EN-RAGE) is associated with cardiovascular morbidity and mortality in hemodialysis patients. In the current study, we tested the hypothesis that S100A12 expressed in vascular smooth muscle in nonatherosclerosis-prone C57BL/6J mice on normal rodent chow diet, but exposed to the metabolic changes of chronic kidney disease (CKD), would develop vascular disease resembling that observed in patients with CKD. Methods: CKD was induced in S100A12 transgenic mice and wild-type littermate mice not expressing human S100A12 by surgical ligation of the ureters. The aorta was analyzed after 7 weeks of elevated BUN (blood urea nitrogen), and cultured aortic smooth muscle cells were studied. Results: We found enhanced vascular medial calcification in S100A12tg mice subjected to CKD. Vascular calcification was mediated, at least in part, by activation of the receptor for S100A12, RAGE (receptor for advanced glycation endproducts), and by enhanced oxidative stress, since inhibition of NADPH-oxidase Nox 1 and limited access of S100A12
\end{abstract}

to RAGE attenuated the calcification and gene expression of osteoblastic genes in cultured vascular smooth muscle cells. Conclusion: S100A12 augments CKD-triggered osteogenesis in murine vasculature, reminiscent of features associated with enhanced vascular calcification in patients with chronic and end-stage kidney disease.

Copyright $\odot 2011$ S. Karger AG, Basel

\section{Introduction}

Chronic kidney disease (CKD) is associated with accelerated atherosclerosis and a high risk of death from cardiovascular disease [1]. Several factors contribute to the vascular disease in $\mathrm{CKD}$, including oxidative stress, inflammation, reduced nitric oxide bioavailability, hypertension and dyslipidemia, among others. Recent epidemiological studies in hemodialysis patients have identified serum S100A12 levels as a significant independent determinant for intimal medial thickness [2] and as an independent predictor for cardiovascular-related mortality, even after adjustment for other confounding inflammatory markers such as white blood cell count, C-reactive protein and interleukin-6 [3]. We first identified S100A12, also known as extracellular newly identified

\section{KARGER}

(C) 2011 S. Karger AG, Basel

Fax +4161306 1234

E-Mail karger@karger.ch

www.karger.com
Accessible online at: www.karger.com/ajn
Marion A. Hofmann Bowman

Section of Cardiology, Department of Medicine

University of Chicago

5841 S. Maryland Avenue MC 6088, Chicago, IL 60637 (USA)

Tel. +1 773834 0807, E-Mail mhofmann@ medicine.bsd.uchicago.edu 
RAGE-binding protein (EN-RAGE) or calgranulin C, as a proinflammatory ligand of the receptor for advanced glycation endproducts (RAGE) [4]. In addition, S100A12 and related family members of the calcium-binding EFhand S100 family are implicated in the regulation of a variety of intracellular and extracellular activities (reviewed in [5]). The importance of RAGE as a mediator of vascular stress and inflammation in atherosclerosis $[6,7]$ and as a mediator of diabetic nephropathy $[8,9]$ was recently shown in mice that lacked RAGE.

Several groups, including ours, have shown that S100A12 is upregulated in vascular smooth muscle cells (VSMC) under pathological conditions such as coronary artery plaque rupture associated with sudden cardiac death [10], in response to LPS [11], in VSMC with a mutation in smooth muscle specific myosin heavy chain MY11 [11], and in human atherosclerosis [12]. Most importantly, transgenic overexpression of human S100A12 in murine vascular smooth muscle demonstrated the critical role for S100A12 in directly mediating enhanced production of reactive oxidative species (ROS) and cytokine production, leading to the formation of aortic aneurysms in C57BL6/J mice [11], and to enhanced atherosclerosis with intimal and medial calcification in atherosclerosis-prone ApoE null mice [12].

These studies strongly suggest that the observed expression of S100A12 in the human vasculature in various diseases is not only a marker of disease, but also a common pathway that promotes vascular damage. In addition, increased serum levels of S100A12 and related S100/ calgranulins have been found in subjects with chronic inflammatory diseases such as rheumatoid arthritis, chronic inflammatory bowel disease, diabetes and vascular disease [13-16]. This is not surprising, given the fact that S100/calgranulins are endogenously expressed and secreted from myeloid cells [17], and therefore may serve as biomarkers for chronic inflammation. To our knowledge, S100A12 has not been studied in mediating vascular disease in patients or mice with CKD, although clinical studies suggest an association of S100A12 with vascular remodeling and cardiovascular mortality in patients with end-stage renal disease undergoing chronic hemodialysis $[2,3]$.

The present study was designed to test the hypothesis that S100A12 may accelerate the CKD-associated damage to arterial blood vessels. We exploited the fact that S100A12 is not present in mice [18], and subjected the previously generated S100A12tg/C57BL6/J (S100A12tg) mice and wild-type C57B6/J littermate (WT) mice to a protocol of renal injury. We found enhanced breakdown of elastic fibers and calcification of the tunica media in S100A12tg mice exposed to the milieu associated with chronic renal disease, while CKD alone did not induce significant vascular pathology in WT mice.

\section{Methods}

\section{Study Groups}

C57BL6/J mice hemizygous for human S100A12 expressed in vascular smooth muscle driven by the SM22 $\alpha$ promoter and WT littermates not expressing the transgene were used for all experiments [11]. All mice were housed at all times in specific pathogen-free barrier facilities and maintained on normal rodent chow with free access to food and water. We induced CKD in 10-week-old mice using a model of reversible unilateral ureteral obstruction [19]. Sham-operated mice underwent repeated anesthesia and laparotomy with inspection of the ureter, but without instrumentation to the ureter. Serum BUN (blood urea nitrogen) was measured and mice were subjected to elevated BUN for approximately 8 weeks until euthanized at the age of 20 weeks. All procedures were carried out with the approval of the Institutional Animal Care and Use Committee of the University of Chicago.

\section{Tissue Preparation}

Serial slides of the aorta were each stained with hematoxylin and eosin, Verhoeff-Van Giessen, Masson's trichrome and alizarin red, and elastic fiber degradation was graded on Verhoeff-Van Giessen-stained slides [11].

Calcification nodules were counted on alizarin red-stained sections of a $10-\mathrm{mm}$ segment of the descending thoracic aorta by 2 blinded investigators and images acquired with a digital camera connected to a microscope (Zeiss) using iVision 4.0 software (BioVision Technologies).

For quantification of mineralization, the aorta was dissected from $1 \mathrm{~mm}$ above the aortic valve to $5 \mathrm{~mm}$ distal from the major branches (inominate, right and left subclavian artery) and all tissue was carefully removed from the aorta under a dissection microscope. The aorta was homogenized and the tissue was decalcified in $0.6 \mathrm{~N} \mathrm{HCl}$ for $24 \mathrm{~h}$; the calcium concentration in the supernatant was determined by the $o$-cresolphthalein complexone (Sigma Aldrich) method. The remaining tissue pellet was solubilized in tissue lysis buffer (Pierce) supplemented with Triton X for Bio-Rad's Protein Assay.

Immunoblotting was performed on whole tissue lysate of a 10$\mathrm{mm}$ segment from the distal thoracic aorta lysed in tissue lysis buffer (Pierce) and a $20-\mu$ protein was loaded for immunoblotting with anti-RAGE IgG (R\&D AF1145), anti-Nox1 IgG (Santa Cruz No. sc10185), anti-S100A12 IgG (Abcam 37657) and anti-GAPDH IgG.

Serum cholesterol and triglyceride concentration were determined using enzymatic kits (Wako Chemical). S100A12 quantities were determined in serum by double-sandwich ELISA using anti-S100A12 IgG (1 $\mu \mathrm{g} / \mathrm{ml}$ Abcam 37657) followed by incubation with biotinylated anti-human EN-RAGE antibody (R\&D). The lower limit of detection of S100A12 was $10 \mathrm{ng} / \mathrm{ml}$ and the intraassay and interassay coefficients of variation were 9 and $12 \%$, respectively. As for ROS, urine was collected from mice in the pres- 


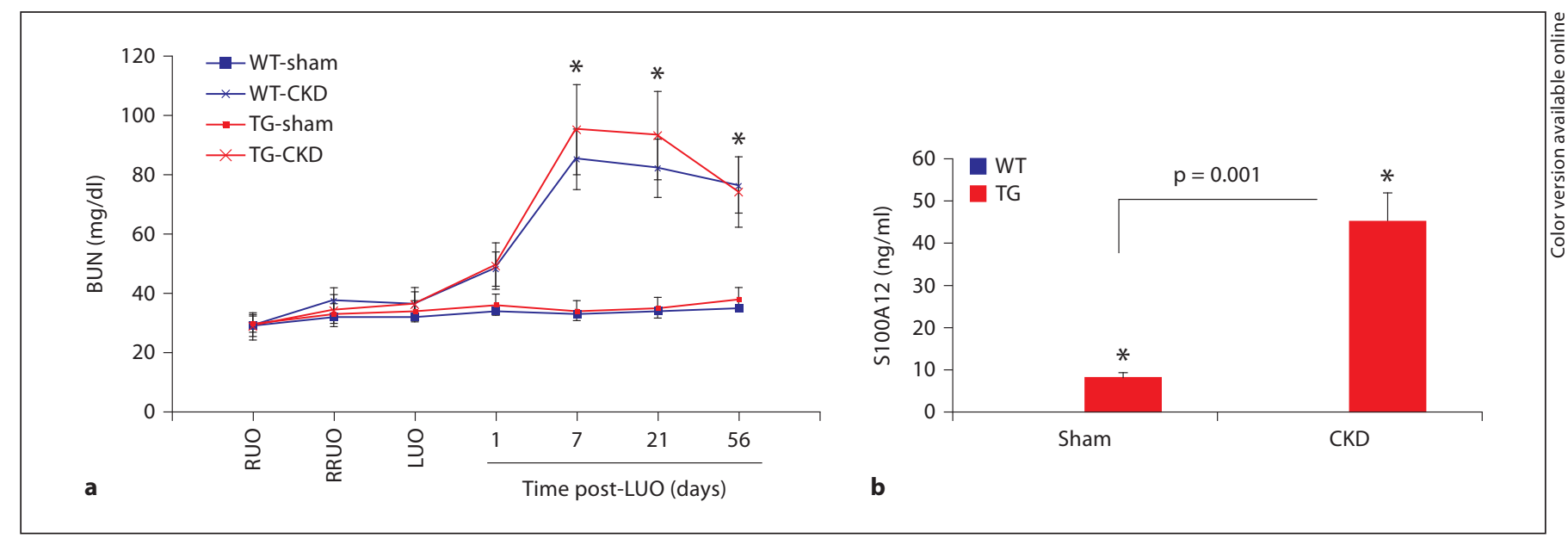

Fig. 1. Development of CKD after ureteral obstruction. a WT and S100A12tg (TG) mice had the right ureter obstructed (RUO) for 6 days followed by the release of obstruction (RRUO), 7 days of recovery and then removal of contralateral kidney function by left ureteral obstruction (LUO). BUN levels were measured post-LUO to assess function of the previously obstructed kidney. b Serum S100A12 was measured in WT and S100A12tg mice at sacrifice. ${ }^{*} \mathrm{p}<0.01$. ence of antioxidant butylated hydroxytoluene and analyzed for 8 -isoprostane by ELISA (Cayman Chemical).

\section{Vascular Smooth Muscle Cells}

Primary mouse aortic VSMC were isolated under sterile conditions from 8-week-old S100A12tg and WT mice [12]. In vitro calcification of VSMC was induced by the addition of $\mathrm{H}_{2} \mathrm{O}_{2}(0.2$ $\mathrm{mM})$ and high phosphate $(2.5 \mathrm{mM})$ to control medium (DMEM containing $10 \% \mathrm{FBS}$ and antibiotics) for 7 days. Where indicated, soluble RAGE, the extracellular ligand-binding domain of RAGE $(20 \mu \mathrm{g} / \mathrm{ml}, \mathrm{R} \& \mathrm{D})$, and bovine serum albumin (BSA, $20 \mathrm{ug} / \mathrm{ml}$, Sigma) was added to the VSMC and repeated every $48 \mathrm{~h}$. The transformation to calcifying cells was characterized as the appearance of nodules upon staining with alizarin red $\mathrm{S}$ on light microscopy, as well as quantified using a colorimetric alizarin red-based method measuring optical densitometry at $405 \mathrm{~nm}$ (Osteogenesis Assay Kit, Millipore). Where indicated, VSMC were transfected with shRNA-Nox1 and control shRNA (SA Bioscience) using the lipofectamine method (Clontech). Transfected VSMC were selected 4 days later by FACS-sorting, employing the GFP-tag coexpressed in the shRNA plasmids prior qRT-PCR for osteoblastic gene expression [12].

\section{Statistics}

At least 6 mice were analyzed per group. All continuous data were reported as means \pm SEM and discrete variables were summarized by percentage. All experiments were performed in at least 3 replicates per group and all cell culture experiments were repeated 3 times. Independent sample t test and one-way analysis of variance were used for mean comparisons between two or multiple groups, respectively. The Bonferroni correction was used to adjust for multiple comparisons. Two-tailed probability values of $\mathrm{p}<0.01$ were considered statistically significant for each test to ensure an overall study significance level of $\mathrm{p}<0.05$. Fisher's exact test was used to analyze the difference frequency of mice.

\section{Results}

\section{Induction of CKD in S100A12tg and WT Mice}

We first investigated the development of CKD in WT and S100A12tg mice in response to surgically induced bilateral renal injury. Mice were subjected to a previously developed protocol of unilateral reversible injury to the right kidney for 6 days, followed by a 7-day period of recovery before the contralateral ureter was irreversible ligated [19]. As shown in figure 1, BUN increased approximately 2.5 -fold in WT and S100A12tg mice compared to sham-operated mice 7 days after left ureteral obstruction $(85 \pm 22,95 \pm 17$ and $35 \pm 12 \mathrm{mg} / \mathrm{dl}$, respectively) and remained significantly elevated until the mice were killed 7 weeks later. The surgery was well tolerated with less than $10 \%$ perioperative mortality in all groups, and the animals maintained normal appearance and weight for the duration of this study (data not shown). We then examined the impact of CKD on serum S100A12 levels. As expected, S100A12 was not detected in the sera of WTsham or WT-CKD animals, but was detectable in the serum of S100A12tg mice with higher levels found in mice that developed CKD (10 and $45 \mathrm{ng} / \mathrm{ml}$, respectively; $\mathrm{p}<$ 0.001). These data suggest that an inflammatory milieu such as CKD facilitates the release of S100A12 from VSMC into serum. These data are in agreement with previous findings that show secretion of $\mathrm{S} 100$ proteins from cells upon activation of protein kinase C [17]. There was no difference in serum cholesterol and serum triglycer- 
ide levels between S100A12tg and WT mice undergoing sham or CKD surgery, respectively (data not shown).

\section{Enhanced Vascular Calcification in S100A12tg Mice} with CKD

The aorta of WT and S100A12tg mice was examined after 7 weeks of exposure to CKD with elevated BUN and in control sham mice. Overall, the architecture of the vasculature was mostly preserved in mice subjected to CKD and we did not notice any early atherosclerotic lesions containing macrophage foam cells.

However, upon staining with alizarin red to detect mineralization and calcification, increased vascular calcification in S100A12tg mice subjected to CKD was observed compared to WT-CKD mice. A representative histology of medial vascular calcification of an S100A12tgCKD animal is shown in figure $2 \mathrm{a}$ (right upper panel). In contrast, we found minimal vascular calcification in WTCKD and S100A12tg-sham, and no vascular calcification in WT-sham aortas after counting calcification nodules in a $10-\mathrm{mm}$ segment of the descending thoracic aorta stained with alizarin red (fig. 2 b).

The intravascular calcium content was further quantified by measuring calcium content in the ascending aorta and arch after careful dissection with removal of all nonvascular tissue, and was normalized to protein content. In sham-operated mice, we found no difference in calcium content between WT and S100A12tg aortas. In WT mice undergoing surgery for CKD, we found a trend toward increased calcium content (1.5-fold compared to sham, $\mathrm{p}=0.08)$ and a significant 3.7-fold increase in aortic calcium content in S100A12tg mice exposed to CKD ( $\mathrm{p}<0.01$; fig. 2c). These data demonstrate that CKD predisposes to vascular calcification and this process is significantly enhanced in the presence of S100A12, rendering the vasculature more susceptible to $\mathrm{CKD}$-mediated injury.

\section{Potential Mechanisms of S100A12-Induced}

Vasculopathy in CKD: Oxidative Stress and

Upregulation of RAGE and Nox1 in the Aorta

Increased oxidative stress is a major finding in CKD. Our previous studies showed that some of the S100A12mediated vascular dysfunction is linked to increased ROS production in VSMC since it is attenuated by treatment with NADPH-oxidase inhibitor apocynin and DPI [12]. Moreover, S100A8/9 has been associated with enhanced oxidative stress in various mammalian cell lines [20]. Therefore, to establish a role for oxidative stress in the S100A12tg-CKD mouse model, we measured urinary 8-isoprostane, which serves as a marker of lipid peroxidation and has been validated in several mouse models. At baseline, S100A12tg (sham) had slightly higher urinary 8-isoprostane compared to WT-sham (1.3-fold increase, $p=0.05)$, and S100A12tg mice subjected to CKD had significantly higher urinary ROS levels compared to WTCKD mice (2.3-fold increase, $\mathrm{p}<0.001$; fig. $3 \mathrm{a})$. While clearly many factors are involved in the initiation and progression of vascular disease in CKD, our findings suggest that at least one mechanism by which S100A12 augments vascular calcification is by promoting oxidative stress that is further enhanced under conditions of impaired renal function.

A pro-oxidative mechanism of S100A12 is supported by its ability to bind and to activate cell surface receptor RAGE [4]. Shaw et al. [21] showed in aortic VSMC that induction of ROS by S100B involves at least in part the NAPDH oxidase system and RAGE. Since S100A12 associates with Nox1 [12], a NADPH-oxidase in VSMC critically involved in generation of ROS, we examined the expression of RAGE, Nox1 and S100A12 in aortic lysate obtained from S100A12tg-CKD and WT-CKD mice. As expected, S100A12 is only present in S100A12tg aorta, but not in WT aorta. Both RAGE and Nox1 are expressed in aortic lysates from S100A12tg and WT mice exposed to CKD, and Noxl is even more abundant in S100A12tg mice (fig. 3b). Interestingly, RAGE and Nox1 were less abundant in aortic tissue lysates of WT mice undergoing sham surgery (data not shown).

Since oxidative stress $[22,23]$ and expression of S100A12 [11] are associated with increased breakdown of vascular elastic fibers and elastin degradation accelerates mineralization of VSMC [24], we graded the elastic fiber breakdown in the vasculature of our four experimental groups. We found significantly increased elastin degradation in the aorta of S100A12tg-sham and S100A12tgCKD mice compared to their respective WT groups (fig. 3d). However, there was no strict colocalization between elastolysis and medial calcification: a representative histology in figure 2a (upper right panel) shows significant medial calcification with intact elastic fibers, and a representative histology shown in figure $3 \mathrm{c}$ demonstrates areas of advanced elastolysis that was free of vascular calcification.

\section{S100A12-Induced Osteogenic Gene Expression in}

VSMC Depends on RAGE and Nox1

There is growing support that VSMC and myofibroblast-like cells, because of their phenotypic plasticity, respond to various stimuli by promoting expression of 

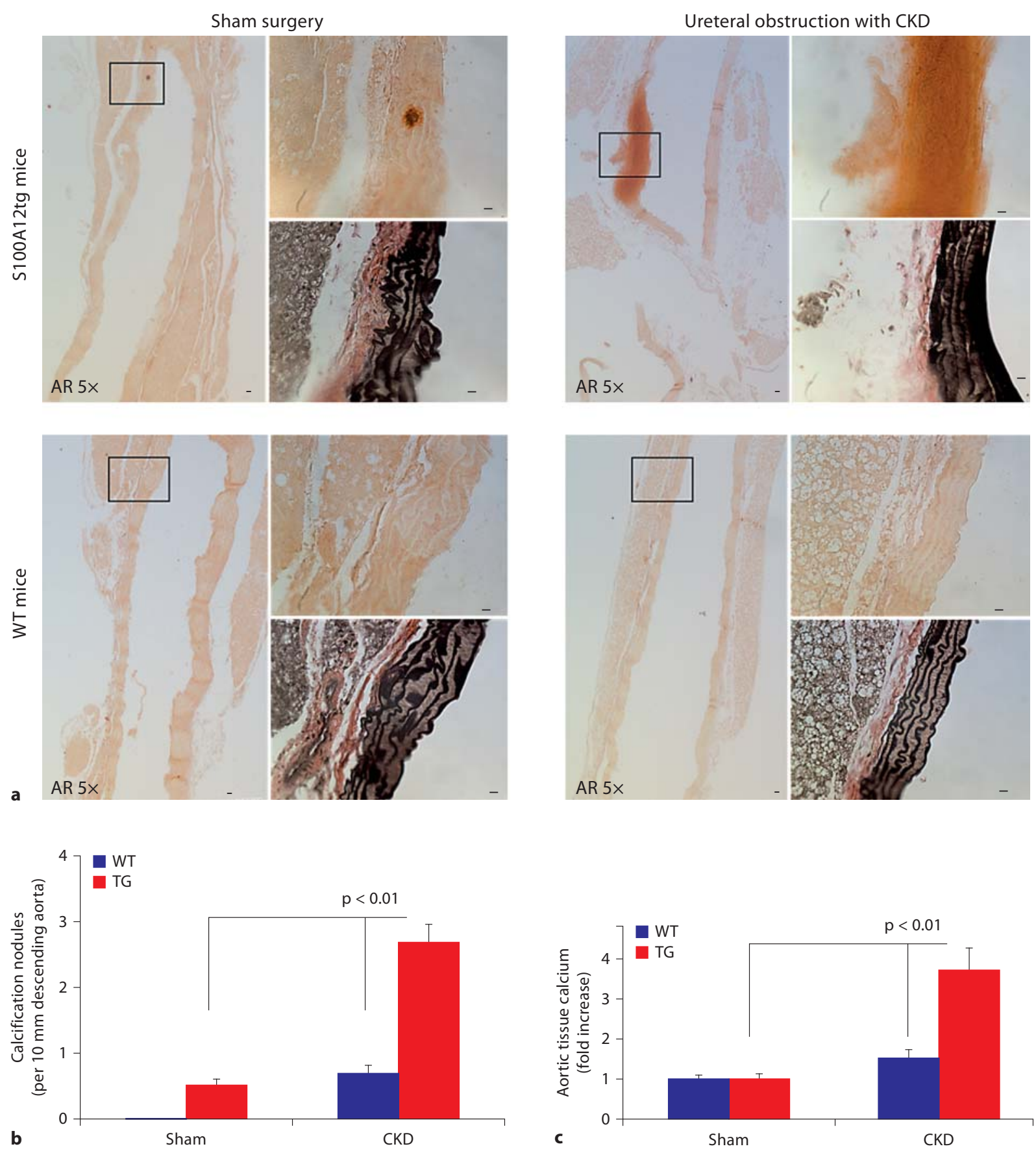

Fig. 2. Advanced medial calcification in the aorta of S100A12tg mice (TG) subjected to CKD (a, upper right panel) but not in WTCKD mice (a, lower right panel). The distal thoracic aorta is shown in $5 \times$ magnification stained for alizarin red (AR), and $40 \times$ magnification insets show calcification upon alizarin red

staining, and elastic fibers in black on Verhoeff-Van Giessenstained serial sections. Scale bars $=10 \mu \mathrm{m}$. b Quantification of calcification nodules seen on alizarin red-stained sections. c Total calcium content was measured in the ascending aorta and arch and normalized to protein content. 


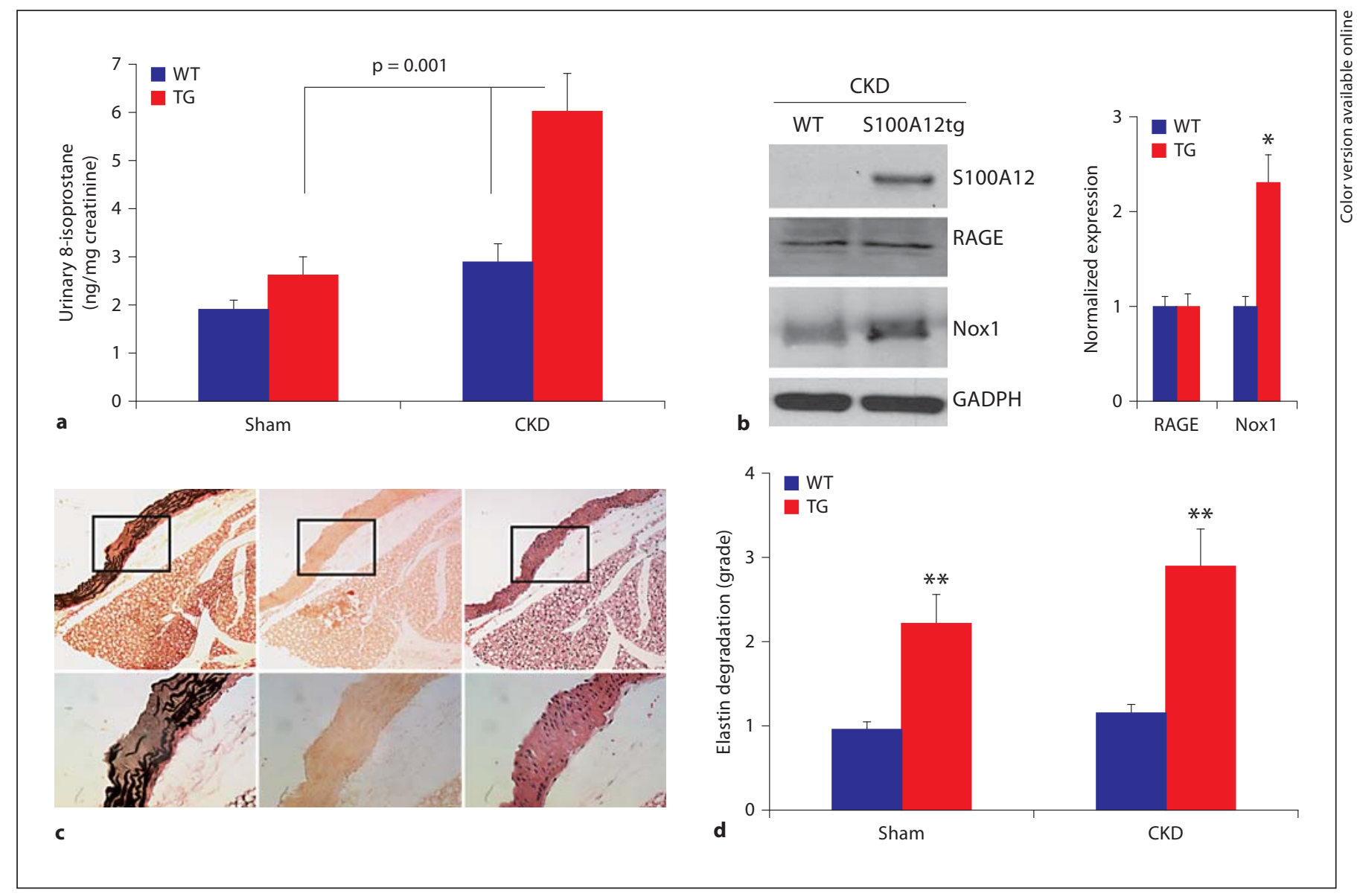

Fig. 3. Effect of S100A12 on oxidative stress. a 8-Isoprostane in the urine of WT and S100A12tg (TG) mice undergoing sham and CKD. b Semiquantitative expression of S100A12, RAGE and Nox1 protein of whole aortic lysate ( ${ }^{*} \mathrm{p}<0.05$ compared to WT). c Representative histology from $\mathrm{S} 100 \mathrm{~A} 12 \mathrm{tg}-\mathrm{CKD}$ aorta showing grade 3 degradation of elastic fibers (fibers are black on Verhoeff-Van
Giessen stain, left panel) with no corresponding calcification on alizarin red stain (middle panel), and hematoxylin and eosin stain (right panel). Original magnification is $10 \times$ with $40 \times$ insets. d Quantification of elastic fiber breakdown shows more elastolysis in S100A12tg aortas $\left({ }^{* *} \mathrm{p}<0.001\right.$ compared to WT; $\mathrm{p}=0.06$ comparing S100A12tg-sham and -CKD). bone-regulating proteins such as alkaline phosphatase, osteocalcin, osteopontin, bone morphogenic proteins, collagen types I and II, and others. Oxidative stress is one of these stimuli and was shown to mediate ossification of VSMC via activation of transcription factor Runx2 [25].

To evaluate if enhanced medial calcification in the aorta of S100A12tg mice with CKD is directly linked to VSMC undergoing a phenotypic conversion, we studied cultured aortic VSMC isolated from S100A12tg and WT mice. VSMC that express S100A12 showed no spontaneous calcification on alizarin red-staining upon culture for 7 days in normal DMEM, and had similar morphology to aortic VSMC from WT mice. However, when cul- tured in osteogenic medium containing $\mathrm{H}_{2} \mathrm{O}_{2}$ and high phosphate, we found increased ossification in S100A12VSMC with alizarin red-staining (data not shown).

Mineralization was quantified by measuring the intracellular total calcium content; we found a 1.8-fold increase in S100A12tg-VSMC mineralization compared to WT-VSMC (fig. 4a). Furthermore, a 2- to 2.5-fold increased gene expression of the osteogenic factors BMP-2, BGLAP and Runx-2 were found in S100A12tg-VSMC compared to WT-VSMC (fig. 4b). We next examined the effect of 'antioxidative' therapy in this cell culture-based model of vascular ossification. To this end, we transfected VSMC with shRNA-Nox1 to knock down the NADPH oxidase subunit critical for smooth muscle ROS produc- 


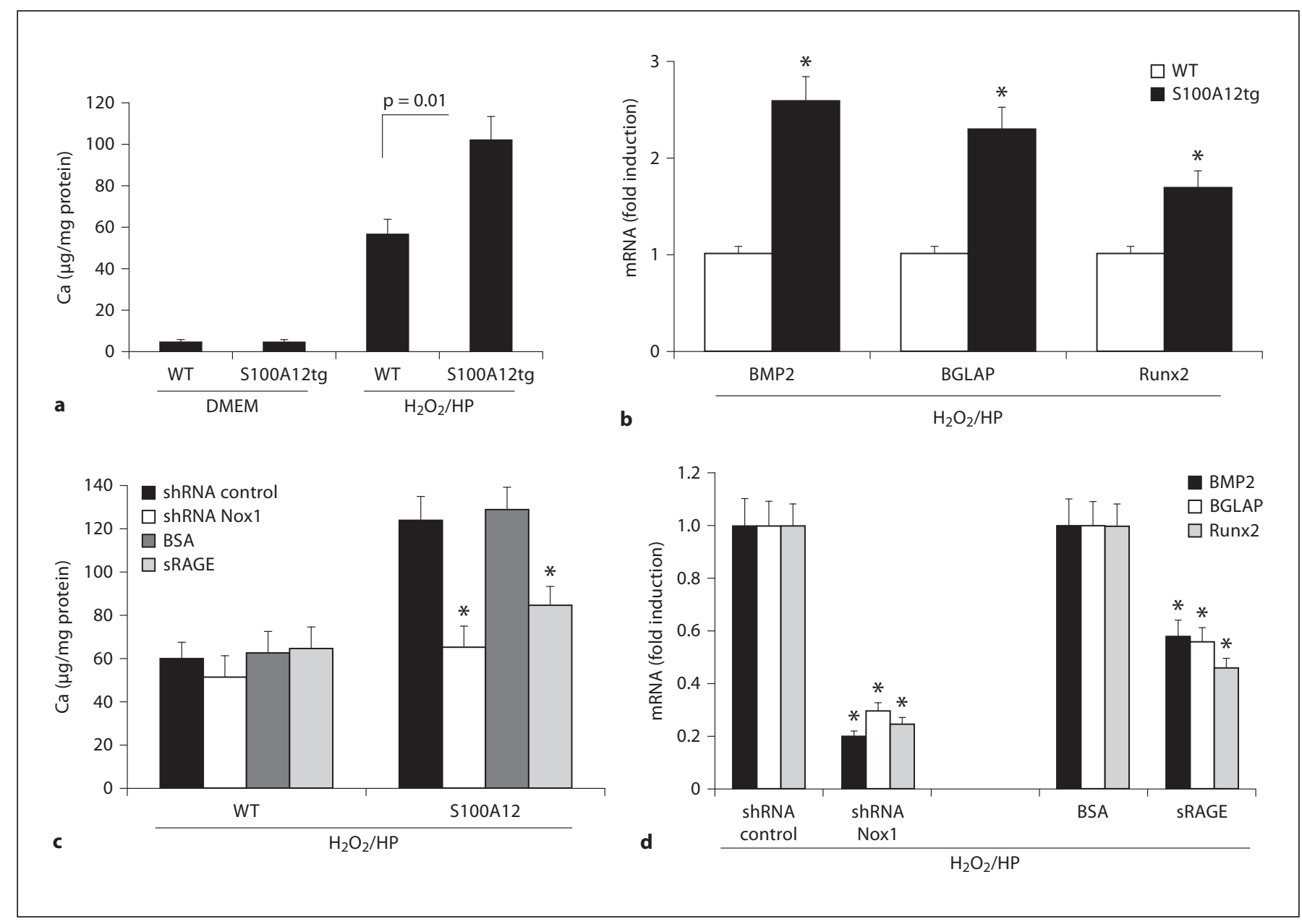

Fig. 4. In vitro calcification and osteoblastic gene expression in cultured VSMC (harvested from the aortas of WT and S100A12tg mice). a Total calcium content of VSMC cultured in DMEM and ossification medium containing $\mathrm{H}_{2} \mathrm{O}_{2}$ and high phosphate $\left(\mathrm{H}_{2} \mathrm{O}_{2} /\right.$ $\mathrm{HP})$. b Quantitative reverse transcription-polymerase reaction for gene expression of bone morphogenic protein 2 (BMP2), bone-gla protein (BGLAP) and Runx2 in VSMC cultured in ossification medium. GAPDH expression was used as internal control $\left({ }^{*} \mathrm{p}<\right.$ 0.001). Effect of shRNA Nox1, shRNA control, soluble RAGE (sRAGE) and BSA on total calcium content (c) and mRNA expression (d) for BMP2, BGLAP and Runx2 ( $\mathrm{p}<0.001)$. VSMC transfected with shRNA plasmids (S100A12 and control) were selected by flow cytometry for GFP expression prior analysis. tion. We found that shRNA-Nox1 abolished mineralization (fig. 4c) and gene expression (fig. 4d) of BMP-2, BGLAP and Runx-2 in S100A12tg-VSMC cultured in osteogenic medium, but had no effect in WT-VSMC. These data suggest that Nox1 is critically important for S100A12-mediated ossification of VSMC.

Since S100A12 is released from S100A12tg-VSMC into the cell culture supernatant when exposed to a 'proinflammatory milieu' $[11,12]$ and RAGE is expressed in VSMC, we examined the effect of soluble RAGE, the extracellular ligand-binding domain, for its ability to prevent VSMC calcification in vitro. As shown in figure 4c, pretreatment of S100A12tg-VSMC with soluble RAGE attenuated calcification by $30 \%$, while control protein BSA had no effect. Importantly, pretreatment with soluble RAGE attenuated significantly the gene expression of Runx-2, BMP-2 and BLAP (fig. 4d). In summary, these data show that S100A12 promotes osteoblastic gene expression in VSMC when cultured in an ossification-stimulating media containing high phosphate and $\mathrm{H}_{2} \mathrm{O}_{2}$. Moreover, this effect is greatly attenuated when S100A12 is quenched by sRAGE or when Nox1 is knocked down in VSMC, suggesting a critical role for RAGE and NADPHoxidase generated oxidative stress. 
Fig. 5. Principle of S100A12-induced ROS in VSMC. S100A12 (red circle in cartoon, online version only) binds and activates RAGE to promote oxidative stress, including translocation of regulatory subunit Rac1 to associate with Nox. S100A12 binds to NADPH-oxidase Nox1 either directly or via binding proteins, as shown recently by our group [12], and the generated ROS promotes VSMC dysfunction, including osteoblastic differentiation. We speculate that S100A12 may act similarly in VSMC to its homolog S100A8/9 in phagocytes where it activates $\mathrm{p} 67^{\text {phox }}$ upon sensing bacteria or other danger molecules resulting in electron transfer from $\mathrm{NADPH}$ to molecular oxygen, and thereby generates a respiratory burst to destroy bacteria [30].

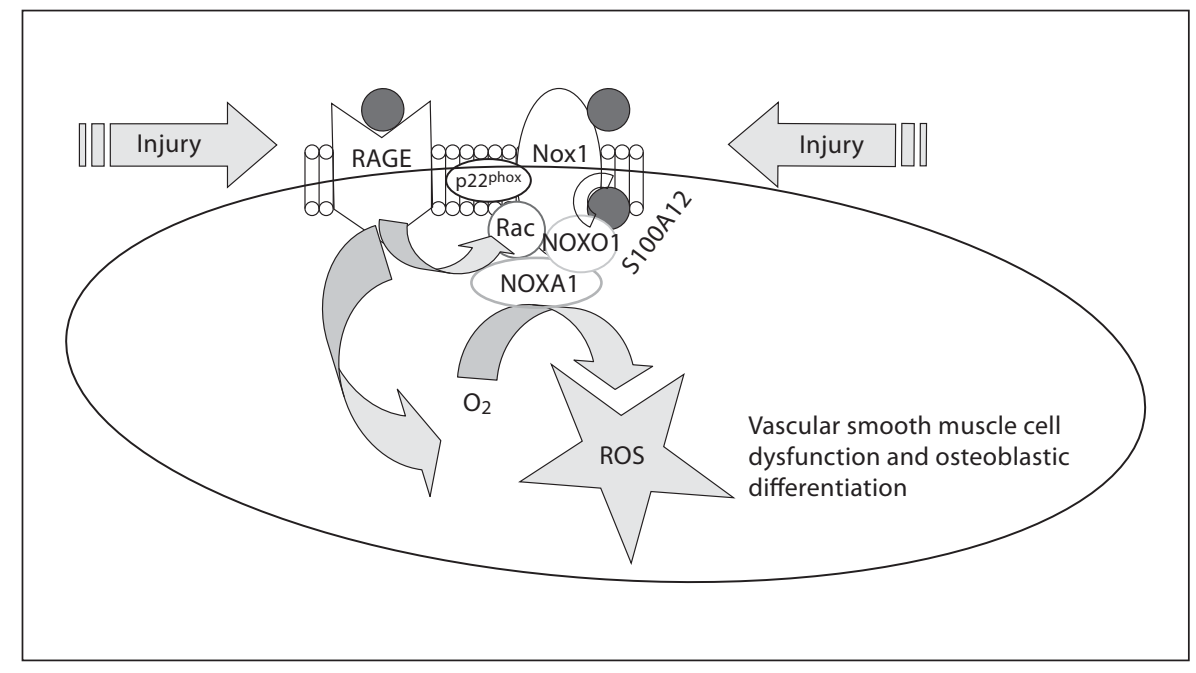

\section{Discussion}

CKD represents a multifactorial mode of injury to the vasculature leading to accelerated vascular disease with high morbidity and mortality. There is mounting evidence that RAGE plays a central role in the pathogenesis of CKD, as well as in the initiation and propagation of atherosclerosis (reviewed in $[26,27]$ ). In regard to CKD, there were two recent clinical observations linking S100A12, a known ligand of RAGE, to accelerated vascular disease (as measured by carotid intimal media thickness) [2] and to increased cardiac mortality, even after correction for other inflammatory biomarkers such as interleukin-6 and C-reactive protein [3].

The present study is the first to directly examine the role of S100A12 in mediating vascular disease in CKD. CKD was achieved by the ureteral obstruction, a widely used model of renal interstitial fibrosis leading to the development and progression of CKD. By utilizing a modified model of reversible ureteral obstruction followed by contralateral permanent obstruction, we had a key advantage in the development of milder CKD that allows the animal to survive a sufficiently long enough time to study long-term effects of CKD on the vasculature in living animals. Our main finding is the significantly enhanced vascular medial calcification in CKD mice that expressed human S100A12 in the blood vessels. In contrast, S100A12tg-sham mice had minimal vascular calcification, possibly explained by a heightened proinflammatory milieu induced by the repeated anesthesia and laparotomy associated with sham surgery. This is in agreement with previously reported findings that
S100A12tg mice of the same C57BL6/J strain had no or minimal vascular calcification when examined in 12-month-old animals [12]. Taken together, S100A12 is not sufficient to induce vascular calcification in a normal environment, but has this ability in a milieu such as CKD or the previously reported hyperlipidemic environment of ApoE null mice [12].

Vascular calcification is a pathological condition that occurs in atherosclerosis and is particularly accelerated in patients with diabetes and/or CKD. Both diabetes and CKD are associated with increased adverse cardiovascular events as well as with increased serum concentration of S100A12 [2, 3, 15]. There are three types of vascular calcification: intimal calcification, medial calcification and valvular calcification. Specifically, calcification of the media usually occurs in the absence of macrophages and hyperlipidemia, and is thought to critically involve VSMC that either undergo a phenotypic switch to osteoblast-like cells or become senescent VSMC with an increased procalcification phenotype [28]. Both mechanisms are likely to be mediated by increased ROS production. In addition, elastin degradation was found to accelerate phosphate-induced mineralization of VSMC [24]. It is interesting to note that in our mouse model we observed increased ROS, increased elastolysis and increased vascular medial calcification. However, elastolysis and calcification did not occur necessarily at the same area within the vasculature.

In addition, our experiments with cultured VSMC showed clearly that the S100A12-mediated calcification process depends on the generation of oxidative stress, likely through pathways involving RAGE and NADPH- 
oxidase Nox1. S100A12 and related S100A8/9 are linked to the generation of ROS. In this regard it is interesting to note that S100A12 constitutes 2-5\% of neutrophilic cytosolic protein and has been linked to antimicrobial and antiparasitic activity [29], although the mechanism is not fully understood. Most relevantly, S100A8/9, two other members of the S100-family with high structural and functional homology to S100A12, have been shown to interact with $\mathrm{p} 67^{\text {phox }}$ to activate Nox $2 / \mathrm{gp} 91^{\text {phox }}$ in phagocytes resulting in ROS production also known as respiratory burst [30]. We speculate that S100A12 may have a similar ability to activate NADPH in VSMC (fig. 5) since we previously showed that S100A12 immunoprecipitates with Nox1 in VSMC [12].

The data presented here demonstrate that S100A12 activates an osteoblastic gene profile in VSMC in a Nox1dependent manner, since knockdown of Nox1 prevented gene expression for Runx2, BMP2 and BGLAP. Nox1 is upregulated in VSMC in response to many stimuli, including advanced glycation endproducts [31] and angiotensin II [32]. Noxl activation is regulated by cytosolic cofactors, including Racl guanosine triphosphates (GTPases) to induce translocation of Nox organizer 1 (analog to $47^{\text {phox }}$ ), and Nox activator 1 (analog to p67 ${ }^{\text {phox }}$ ) from the cytosol to the membrane-bound Nox1 [33]. Interestingly, blocking antibody to $\mathrm{p} 47^{\text {phox }}$ was previously shown to block S100B-induced phosphorylation of Janus kinase 2 in VSMC, suggesting that $\mathrm{p} 47^{\mathrm{phox}} /$ (Nox organizer 1)-mediated signaling is critical for S100B-induced oxidative stress in VSMC [21]. Moreover, activation of RAGE by it ligands leads to activation of Racl with several downstream effects, including activation of NADPH and enhanced oxidative stress $[34,35]$.

In conclusion, mice exposed to surgically induced CKD develop accelerated vascular medial calcification when human S100A12 is expressed in vascular smooth muscle in genetically manipulated mice. Our findings of enhanced oxidative stress, and increased expression of osteoblastic genes in VSMC in a RAGE- and NADPHdependent manner may explain, at least in part, the association of elevated S100A12 in hemodialysis patients with increased cardiovascular mortality which was reported in a recent clinical observational study [3]. Furthermore, the mRNA level of S100A12 in peripheral blood cells was a strong predictor of obstructive coronary artery disease in a multicenter validation study involving 526 nondiabetic patients with angiographic-proven obstructive coronary artery disease [36], suggesting a broader role for S100A12 in mediating vascular disease that is not limited to patients with end-stage renal disease treated with hemodialysis.

\section{Acknowledgements}

We thank Judy Earle for her expert technical assistance with the histology studies. We thank Dr. S.E. Fedson for reviewing and editing the manuscript.

\section{Source of Funding}

This work was supported by funding from the National Institute of Health (M.A.H.B.: K08 HL090917-02, G.K.: K08HL098565-01), and by the GlaxoSmithKline Research \& Education Foundation for Cardiovascular Diseases (M.A.H.B.).

\section{Disclosure Statemtent}

None.

\section{References}

1 Go AS, Chertow GM, Fan D, McCulloch CE, Hsu CY: Chronic kidney disease and the risks of death, cardiovascular events, and hospitalization. N Engl J Med 2004;351: 1296-1305.

2 Mori Y, Kosaki A, Kishimoto N, Kimura T, Iida K, Fukui M, Nakajima F, Nagahara M, Urakami M, Iwasaka T, Matsubara H: Increased plasma S100A12 (EN-RAGE) levels in hemodialysis patients with atherosclerosis. Am J Nephrol 2009;29:18-24.

-3 Nakashima A, Carrero JJ, Qureshi AR, Miyamoto T, Anderstam B, Barany P, Heimburger O, Stenvinkel P, Lindholm B: Effect of circulating soluble receptor for advanced glycation end products (sRAGE) and the proinflammatory RAGE ligand (EN-RAGE, S100A12) on mortality in hemodialysis patients. Clin J Am Soc Nephrol 2010;12:22132219.

4 Hofmann MA, Drury S, Fu C, Qu W, Taguchi A, Lu Y, Avila C, Kambham N, Bierhaus A, Nawroth P, Neurath MF, Slattery T, Beach D, McClary J, Nagashima M, Morser J, Stern D, Schmidt AM: RAGE mediates a novel proinflammatory axis: a central cell surface receptor for S100/calgranulin polypeptides. Cell 1999;97:889-901.
5 Leclerc E, Fritz G, Vetter SW, Heizmann CW: Binding of S100 proteins to RAGE: an update. Biochim Biophys Acta 2009;1793:9931007.

6 6 Harja E, Bu DX, Hudson BI, Chang JS, Shen X, Hallam K, Kalea AZ, Lu Y, Rosario RH, Oruganti S, Nikolla Z, Belov D, Lalla E, Ramasamy R, Yan SF, Schmidt AM: Vascular and inflammatory stresses mediate atherosclerosis via RAGE and its ligands in apoE $\mathrm{E}^{-/-}$ mice. J Clin Invest 2008;118:183-194. 
7 Soro-Paavonen A, Watson AM, Li J, Paavonen K, Koitka A, Calkin AC, Barit D, Coughlan MT, Drew BG, Lancaster GI, Thomas M, Forbes JM, Nawroth PP, Bierhaus A, Cooper ME, Jandeleit-Dahm KA: Receptor for advanced glycation end products (RAGE) deficiency attenuates the development of atherosclerosis in diabetes. Diabetes 2008;57:2461-2469.

-8 Reiniger N, Lau K, McCalla D, Eby B, Cheng B, Lu Y, Qu W, Quadri N, Ananthakrishnan R, Furmansky M, Rosario R, Song F, Rai V, Weinberg A, Friedman R, Ramasamy R, D'Agati V, Schmidt AM: Deletion of the receptor for advanced glycation end products reduces glomerulosclerosis and preserves renal function in the diabetic OVE26 mouse. Diabetes 2010;59:2043-2054.

-9 Sourris KC, Morley AL, Koitka A, Samuel P, Coughlan MT, Penfold SA, Thomas MC, Bierhaus A, Nawroth PP, Yamamoto H, Allen TJ, Walther T, Hussain T, Cooper ME, Forbes JM: Receptor for AGEs (RAGE) blockade may exert its renoprotective effects in patients with diabetic nephropathy via induction of the angiotensin II type 2 (AT2) receptor. Diabetologia 2010;53:2442-2451.

10 Burke AP, Kolodgie FD, Zieske A, Fowler DR, Weber DK, Varghese PJ, Farb A, Virmani R: Morphologic findings of coronary atherosclerotic plaques in diabetics: a postmortem study. Arterioscler Thromb Vasc Biol 2004;24:1266-1271.

-11 Hofmann Bowman M, Wilk J, Heydemann A, Kim G, Rehman J, Lodato JA, Raman J, McNally EM: S100A12 mediates aortic wall remodeling and aortic aneurysm. Circ Res 2010;106:145-154.

-12 Hofmann Bowman MA, Gawdzik J, Bukhari U, Husain AN, Toth PT, Kim G, Earley J, McNally EM: S100A12 in vascular smooth muscle accelerates vascular calcification in apolipoprotein E-null mice by activating an osteogenic gene regulatory program. Arterioscler Thromb Vasc Biol 2011;31:337-344.

- 13 Foell D, Kane D, Bresnihan B, Vogl T, Nacken W, Sorg C, Fitzgerald O, Roth J: Expression of the pro-inflammatory protein S100A12 (EN-RAGE) in rheumatoid and psoriatic arthritis. Rheumatology (Oxford) 2003;42:1383-1389.

14 Foell D, Kucharzik T, Kraft M, Vogl T, Sorg C, Domschke W, Roth J: Neutrophil derived human S100A12 (EN-RAGE) is strongly expressed during chronic active inflammatory bowel disease. Gut 2003;52:847-853.

-15 Basta G, Sironi AM, Lazzerini G, Del Turco S, Buzzigoli E, Casolaro A, Natali A, Ferrannini E, Gastaldelli A: Circulating soluble receptor for advanced glycation end products is inversely associated with glycemic control and S100A12 protein. J Clin Endocrinol Metab 2006;91:4628-4634.
6 Foell D, Ichida F, Vogl T, Yu X, Chen R, Miyawaki T, Sorg C, Roth J: S100A12 (ENRAGE) in monitoring Kawasaki disease. Lancet 2003;361:1270-1272.

17 Rammes A, Roth J, Goebeler M, Klempt M Hartmann M, Sorg C: Myeloid-related protein (MRP) 8 and MRP14, calcium-binding proteins of the $\mathrm{S} 100$ family, are secreted by activated monocytes via a novel, tubulin-dependent pathway. J Biol Chem 1997;272: 9496-9502.

18 Fuellen G, Nacken W, Sorg C, Kerkhoff C: Computational searches for missing orthologs: the case of S100A12 in mice. OMICS 2004;8:334-340.

19 Puri TS, Shakaib MI, Chang A, Mathew L, Olayinka O, Minto AW, Sarav M, Hack BK, Quigg RJ: Chronic kidney disease induced in mice by reversible unilateral ureteral obstruction is dependent on genetic background. Am J Physiol Renal Physiol 2010; 298:F1024-F1032.

20 Ghavami S, Eshragi M, Ande SR, Chazin WJ, Klonisch T, Halayko AJ, McNeill KD, Hashemi M, Kerkhoff C, Los M: S100A8/A9 induces autophagy and apoptosis via ROS-mediated cross-talk between mitochondria and lysosomes that involves BNIP3. Cell Res 2010;20:314-331.

21 Shaw SS, Schmidt AM, Banes AK, Wang X, Stern DM, Marrero MB: S100B-RAGE-mediated augmentation of angiotensin II-induced activation of JAK2 in vascular smooth muscle cells is dependent on PLD2. Diabetes 2003;52:2381-2388.

22 Hofmann MA, Lalla E, Lu Y, Gleason MR, Wolf BM, Tanji N, Ferran LJ Jr, Kohl B, Rao V, Kisiel W, Stern DM, Schmidt AM: Hyperhomocysteinemia enhances vascular inflammation and accelerates atherosclerosis in a murine model. J Clin Invest 2001;107: 675-683.

-23 Ke XD, Foucault-Bertaud A, Genovesio C, Dignat-George F, Lamy E, Charpiot P: Homocysteine modulates the proteolytic potential of human arterial smooth muscle cells through a reactive oxygen species dependant mechanism. Mol Cell Biochem 2010;335: 203-210.

24 Hosaka N, Mizobuchi M, Ogata H, Kumata C, Kondo F, Koiwa F, Kinugasa E, Akizawa T: Elastin degradation accelerates phosphate-induced mineralization of vascular smooth muscle cells. Calcif Tissue Int 2009; 85:523-529.

25 Byon CH, Javed A, Dai Q, Kappes JC, Clemens TL, Darley-Usmar VM, McDonald JM, Chen Y: Oxidative stress induces vascular calcification through modulation of the osteogenic transcription factor Runx 2 by AKT signaling. J Biol Chem 2008;283:1531915327.

-26 D’Agati V, Schmidt AM: RAGE and the pathogenesis of chronic kidney disease. Nat Rev Nephrol 2010;6:352-360.
27 Yan SF, Ramasamy R, Schmidt AM: The RAGE axis: a fundamental mechanism signaling danger to the vulnerable vasculature. Circ Res 2010;106:842-853.

28 Burton DG, Matsubara H, Ikeda K: Pathophysiology of vascular calcification: Pivotal role of cellular senescence in vascular smooth muscle cells. Exp Gerontol 2010;45: 819-824.

29 Gottsch JD, Eisinger SW, Liu SH, Scott AL: Calgranulin $\mathrm{C}$ has filariacidal and filariastatic activity. Infect Immun 1999;67:66316636.

30 Berthier S, Paclet MH, Lerouge S, Roux F, Vergnaud S, Coleman AW, Morel F: Changing the conformation state of cytochrome b558 initiates NADPH oxidase activation: MRP8/MRP14 regulation. J Biol Chem 2003; 278:25499-25508.

- 31 San Martin A, Foncea R, Laurindo FR, Ebensperger R, Griendling KK, Leighton F: Nox1-based NADPH oxidase-derived superoxide is required for VSMC activation by advanced glycation end-products. Free Radic Biol Med 2007;42:1671-1679.

32 Lassegue B, Sorescu D, Szocs K, Yin Q, Akers M, Zhang Y, Grant SL, Lambeth JD, Griendling KK: Novel gp91(phox) homologues in vascular smooth muscle cells: nox 1 mediates angiotensin II-induced superoxide formation and redox-sensitive signaling pathways. Circ Res 2001;88:888-894.

33 Gianni D, Diaz B, Taulet N, Fowler B, Courtneidge SA, Bokoch GM: Novel p47(phox)related organizers regulate localized NADPH oxidase 1 (Nox1) activity. Sci Signal 2009;2:ra54.

34 Hudson BI, Kalea AZ, Del Mar Arriero M, Harja E, Boulanger E, D'Agati V, Schmidt AM: Interaction of the RAGE cytoplasmic domain with diaphanous-1 is required for ligand-stimulated cellular migration through activation of Rac1 and Cdc42. J Biol Chem 2008;283:34457-34468.

35 Wautier MP, Chappey O, Corda S, Stern DM, Schmidt AM, Wautier JL: Activation of NADPH oxidase by AGE links oxidant stress to altered gene expression via RAGE. Am J Physiol Endocrinol Metab 2001;280:E685E694.

- 36 Rosenberg S, Elashoff MR, Beineke P, Daniels SE, Wingrove JA, Tingley WG, Sager PT, Sehnert AJ, Yau M, Kraus WE, Newby LK, Schwartz RS, Voros S, Ellis SG, Tahirkheli N, Waksman R, McPherson J, Lansky A, Winn ME, Schork NJ, Topol EJ: Multicenter validation of the diagnostic accuracy of a blood-based gene expression test for assessing obstructive coronary artery disease in nondiabetic patients. Ann Intern Med 2010;153:425-434. 